\title{
Appendix to Null and overt subject pronouns in topic continuity and topic shift: An investigation of the narrative productions of Italian Natives, Greek Natives and near-native second language speakers of Italian with Greek as a first language
}

Elisa Di Domenico, Ioli Baroncini \& Andrea Capotorti

This document file contains additional figures pertaining to 'Null and overt subject pronouns in topic continuity and topic shift: An investigation of the narrative productions of Italian Natives, Greek Natives and near-native second language speakers of Italian with Greek as a first language'.

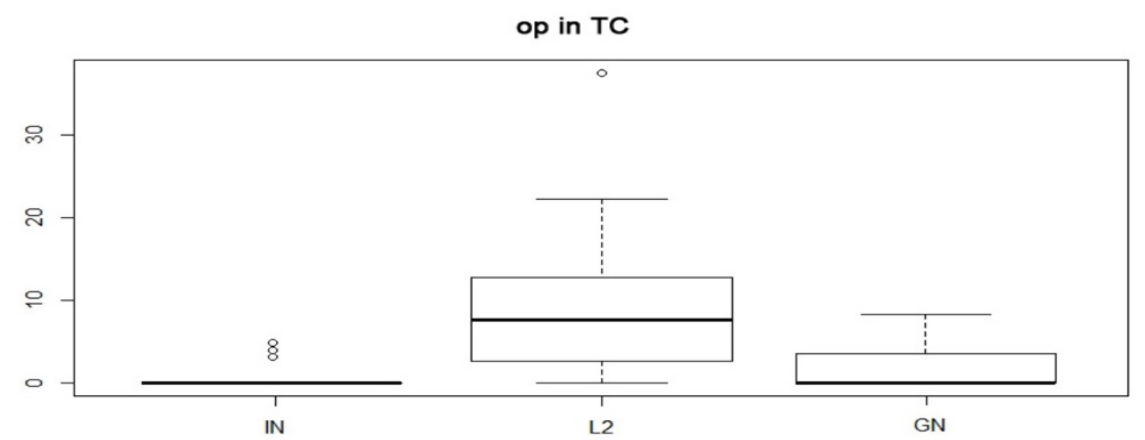

Figure 1: Overt pronouns in topic continuity.

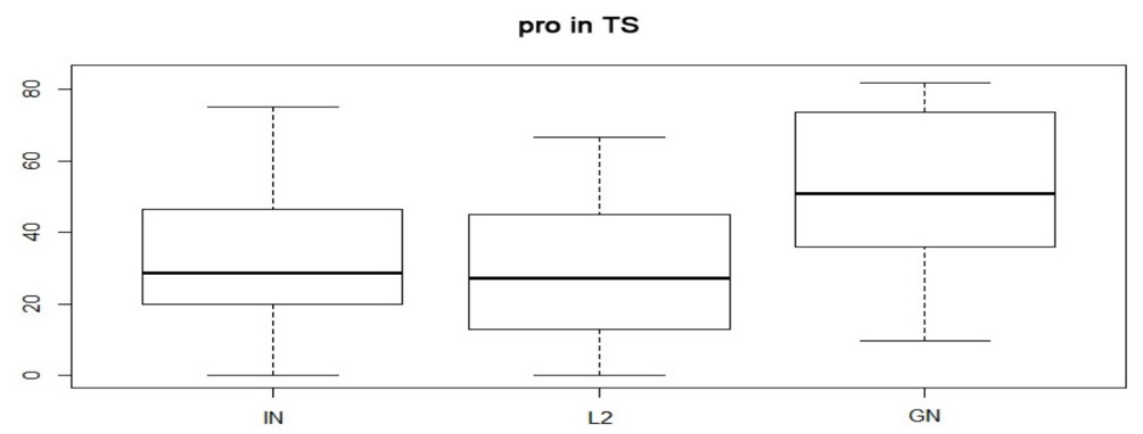

Figure 2: pro in topic shift. 


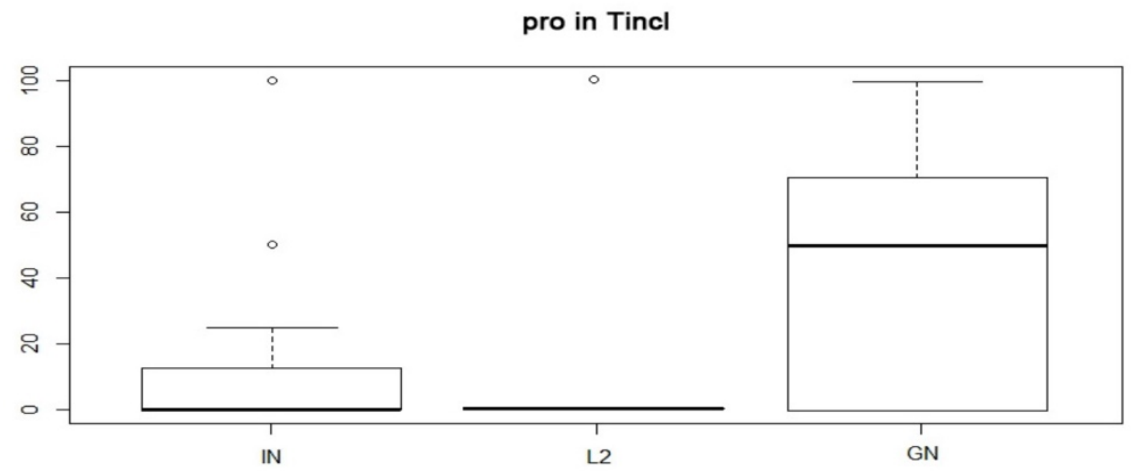

Figure 3: pro in Tincl.

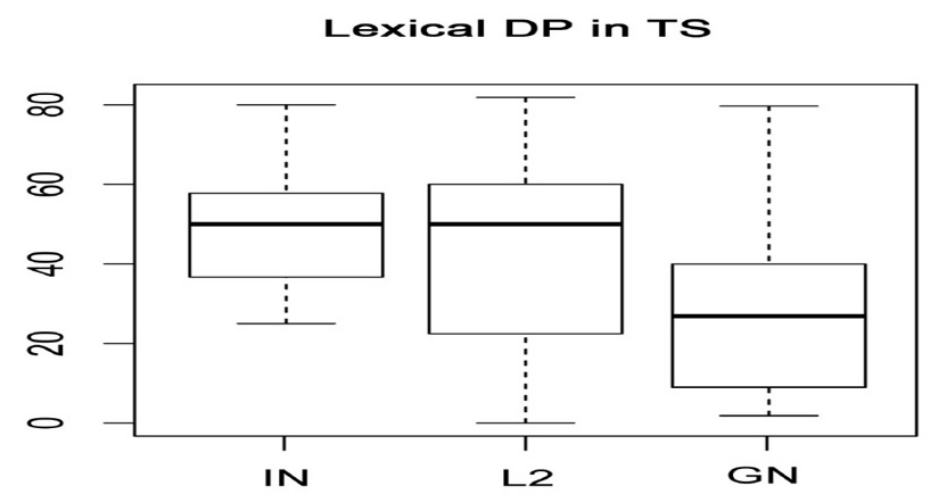

Figure 4: Lexical DPs in topic shift.
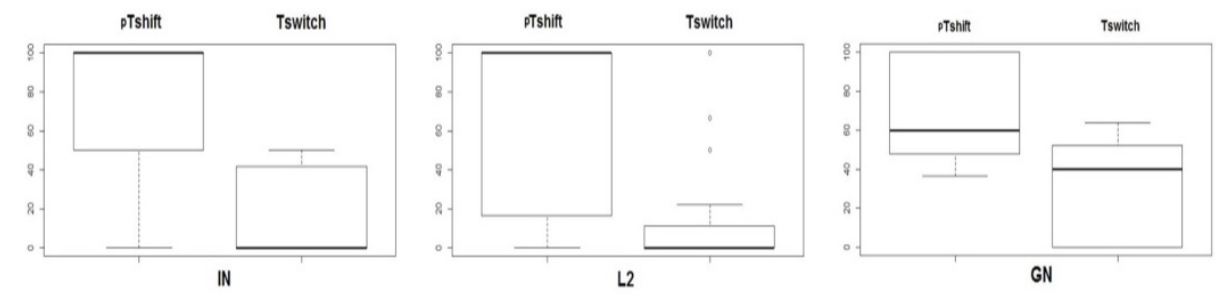

Figure 5: pro in proper topic shift and topic switch. 

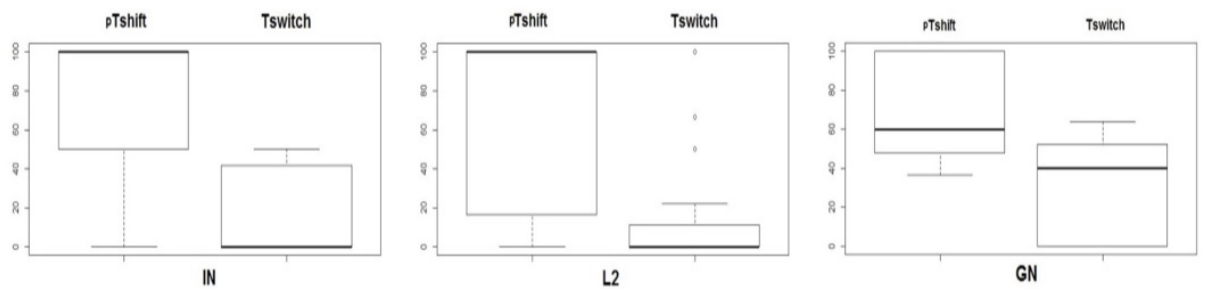

Figure 6: Overt pronouns in the different referents conditions in the three groups. 